Review Article

\title{
Efficacy of high intensity laser therapy in the management of foot ulcers: a systematic review
}

\author{
Mohamed Salaheldien Alayat, PhD ${ }^{1)}$, Ahmed Mohamed El-Sodany, PhD $^{2}$, \\ Anwar Abdelgayed Ebid, PhD $^{3)}$, Tamer Mohamed Shousha, $\mathrm{PhD}^{4,5)}$,
} Abdelgalil Allam Abdelgalil, $\mathrm{PhD}^{2}$, , Hammad Alhasan, $\mathrm{MSc}^{2)}$, Mansour Abdullah Alshehri, MSc ${ }^{2) *}$

1) Department of Basic Science, Faculty of Physical Therapy, Cairo University, Egypt

2) Physiotherapy Department, Faculty of Applied Medical Science, Umm Al-Qura University: Mecca, Saudi Arabia

3) Department of Physical Therapy for Surgery, Faculty of Physical Therapy, Cairo University, Egypt

4) Physiotherapy Department, College of Health Sciences, University of Sharjah, United Arab Emirates

5) Physical Therapy Department for Orthopedic Disorders, Faculty of Physical Therapy, Cairo University, Egypt

\begin{abstract}
Purpose] The aim of this systematic review was to assess the efficacy of high intensity laser therapy (HILT) on wound surface area in patients with foot ulcers. [Methods] Four databases including PubMed, MEDLINE, the Cochrane library, and the Physiotherapy Evidence Database (PEDro) were searched up to the end of April 2018 to identify relevant studies. Studies were included if they met the following criteria: randomised controlled trial (RCT), assessed the efficacy of HILT in patients with foot ulcers, evaluated wound surface area, and written in English language with available full text. The PEDro scale was used to evaluate the quality of studies. [Results] A total of three RCTs met the inclusion criteria, with two studies of the efficacy of HILT in adult patients with diabetic foot ulcers and one in spina bifida children with neuropathic foot ulcers. According to the PEDro scale assessment, all three studies were rated as a fair quality. All studies found that HILT provided significantly better outcomes compared to sham laser or standard medical therapy. [Conclusion] This systematic review suggests that HILT is an effective modality for wound healing in patients with foot ulcers, but further large-scale studies are required to confirm its efficacy.

Key words: High intensity laser therapy, Foot ulcers, Diabetes
\end{abstract}

(This article was submitted May 29, 2018, and was accepted Jul. 20, 2018)

\section{INTRODUCTION}

Foot ulcers are considered as a serious health problem and a complication frequently observed in diabetic patients ${ }^{1)}$. Often patients with diabetes have lower-limb amputations preceded by foot ulceration ${ }^{2}$, thus, appropriate management of foot ulcers is a priority. Annually, more than $2 \%$ of patients with diabetes develop new foot ulcers ${ }^{3)}$, with the costs to treat an adult male with a new foot ulcer during the two years after diagnosis estimated to be $\$ 28$ thousand ${ }^{4}$. As there are multifactorial causes and high risk of recurrence, treating patients with foot ulcers is challenging, impacting on the health care system and community ${ }^{5,6)}$. It has been reported that ulceration is caused by multiple factors working together such as neuropathy, peripheral vascular disorders, callus, oedema, and deformity ${ }^{7)}$, therefore, proper prevention strategies and low-cost interventions are required.

*Corresponding author. Mansour Abdullah Alshehri (E-mail: mamshehri@uqu.edu.sa)

(C2018 The Society of Physical Therapy Science. Published by IPEC Inc.

(c) (1) $\odot$ This is an open-access article distributed under the terms of the Creative Commons Attribution Non-Commercial No Derivacc) 
High intensity laser therapy (HILT) provided by many devices such as Nd: YAG (neodymium-doped yttrium aluminium garnet) is considered as a safe and an effective intervention modality. It has a high peak power ( $3 \mathrm{~kW})$ and a wavelength of $1,064 \mathrm{~nm}$ which assists to provide its thermal, chemical and mechanical effects ${ }^{8}$. Many studies have reported the therapeutic effects of HILT in treating numerous musculoskeletal and some neurological disorders. It has been reported that HILT can relieve pain in patients with shoulder ${ }^{9)}$, neck ${ }^{10)}$ and lower back deriders ${ }^{11)}$, as well as improve the quality of life in knee osteoarthritis patients $^{12)}$. In addition, some studies reported its efficacy in nerve recovery ${ }^{13)}$, wound healing ${ }^{14)}$, decreasing prostaglandin levels in blood ${ }^{15)}$, bone density ${ }^{16)}$ and reducing adhesions ${ }^{17)}$. Although numerous studies have investigated the effects of HILT, no systematic review has been conducted to assess its efficacy on foot ulcers. Therefore, the aim of this systematic review is to evaluate the efficacy of HILT in the management of patients with foot ulcers.

\section{METHODS}

This study was registered in the International Prospective Register of Systematic Reviews (PROSPERO) under number CRD42018093849. Four databases were searched up to the end of April 2018 including PubMed, MEDLINE, the Cochrane Central Register of Controlled Trials (CENTRAL), and the Physiotherapy Evidence Database (PEDro). In addition, the reference lists of all included studies were searched for any further relevant studies. Search terms were determined based on the inclusion and exclusion criteria. Table 1 shows the search terms and method used in PubMed.

Studies were eligible for inclusion in this study if they met the following criteria: the design of the study must be an RCT assessing the effectiveness of HILT in patients with foot ulcers and the protocol of HILT should be clearly explained, studies must have primary outcome measure of wound surface area (WSA), and all included studies must be written in English language with available full text. Studies were excluded if they were observational and non-randomised studies or used low level laser therapy (LLLT), foot pain without ulcers, did not use wound surface area as outcome measures, were non-English language studies and without available full text.

The titles and abstracts of articles were independently screened by two researchers to assess their eligibility against the defined inclusion and exclusion criteria. When an abstract did not include sufficient data regarding the inclusion and exclusion criteria, the full text was screened. EndNote software was used to delete any possible duplicates in the search results. All RCTs that met the inclusion and exclusion criteria were carefully assessed and a standardised form was used to extract relevant data from studies that met the inclusion criteria. The risk of bias (the methodological quality) of the included studies was rated using the PEDro scale by two independent reviewers (MAA and HA). The PEDro scale has 11 items (questions yes and no), and the total score ranges between zero and ten ${ }^{18)}$. The quality of the included studies was rated as low quality ( score $=$ three or less), fair quality (score $=$ four to five) or high quality (score $=$ six or more).

\section{RESULTS}

A total of 445 articles were identified using healthcare database searches and other sources. Following the removal of duplicate articles, 251 articles were screened by reading the titles and abstracts. Seven articles were initially eligible and after full text assessment, only three studies ${ }^{19-21)}$ met the inclusion criteria, while four articles were excluded because they used low level laser therapy (LLLT). Figure 1 shows a flow diagram of the study selection process.

Table 1. Search terms and method (PubMed)

\begin{tabular}{ll}
\hline Step & Search terms and method \\
\hline$\# 1$ & $\begin{array}{l}\text { Search randomized controlled trial [Publication Type] } \\
\text { OR randomised controlled trial [Publication Type] }\end{array}$ \\
$\# 2$ & $\begin{array}{l}\text { Search foot ulcer [Title/Abstract] OR foot pain } \\
\text { [Title/Abstract] OR foot wound [Title/Abstract] }\end{array}$ \\
& $\begin{array}{l}\text { Search laser therapy [Title/Abstract] OR high intensity } \\
\text { laser therapy [Title/Abstract] OR high power laser } \\
\text { therapy [Title/Abstract] OR Nd:YAG [Title/Abstract] }\end{array}$ \\
OR class IV laser [Title/Abstract] \\
\#4 & $\begin{array}{l}\text { Search low level laser therapy [Title/Abstract] } \\
\text { 1 and 2 and 3 NOT 4 }\end{array}$ \\
\hline
\end{tabular}

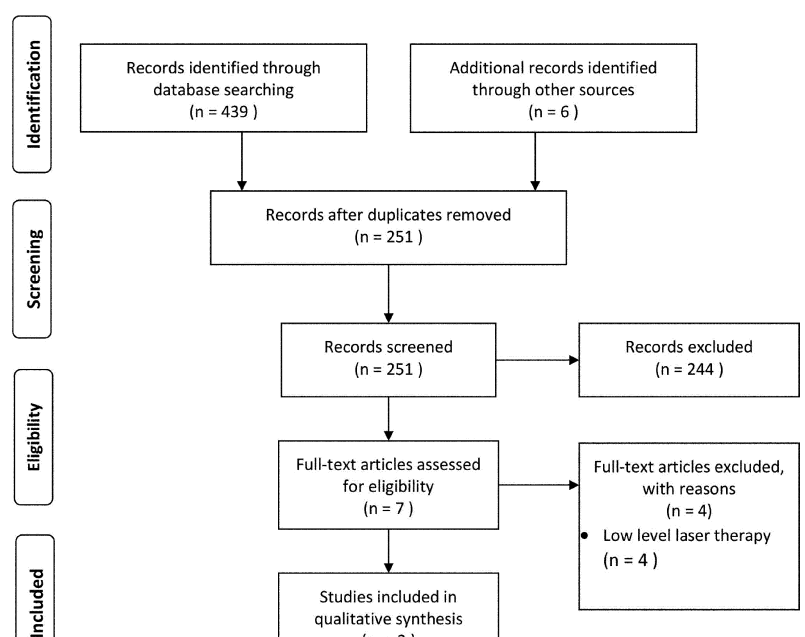

$(n=3)$

Fig. 1. Flow diagram of the study selection process. 
Three studies ${ }^{19-21)}$ with a total of 122 patients were included in this review, all of which were published during the last ten years. Two studies investigated the effect of HILT in patients with diabetic foot ulcers ${ }^{19,20)}$ and the third study was conducted on spina bifida children with neuropathic foot ulcers ${ }^{21)}$. All studies assessed the efficacy of the intervention on WSA, while wound appearance (WA) was assessed in only one study ${ }^{21}$. All studies used HILT as the main intervention compared with sham laser in two studies ${ }^{20,21)}$, while one study assessed HILT versus standard medical therapy ${ }^{19)}$. In terms of the laser protocol, all studies used three phases during laser application, comprising an initial phase (manual scanning), intermediate phase (fixed points) and manual scanning (final phase). All studies used Nd-YAG laser. Table 2 summarises the main characteristics of the included studies.

As the heterogeneity was high and there were a low number of included studies, meta-analysis (quantitative) was not possible, so a qualitative synthesis of the main results was performed as shown in Table 2. When HILT was compared to placebo laser, two studies found that the combination of HILT with standard medical therapy provided better outcomes in terms of $\mathrm{WSA}^{20,21)}$ and $\mathrm{WA}^{21)}$ than sham laser with standard medical therapy. Another study compared HILT alone to standard medical therapy and found that HILT was more effective $(p<0.05)$ than standard medical therapy in patients with chronic diabetic foot ulcers in terms of WSA improvement ${ }^{19}$ ). The quality of the included studies was assessed using the PEDro scale; all studies were rated as fair quality. All studies ${ }^{19-21)}$ failed to meet some component of the PEDro scale involving the allocation concealment, blinding (participants, therapists or assessors) and intention to treat analysis. Table 3 demonstrates the risk of bias assessment of the included studies.

Table 2. Characteristics of included studies

\begin{tabular}{|c|c|c|c|c|}
\hline Study & Population & $\begin{array}{l}\text { Measured } \\
\text { variables }\end{array}$ & Intervention & $\begin{array}{l}\text { Summary of results } \\
\text { ( } \mathrm{p} \text { value; mean } \pm \mathrm{SD} \text { ) }\end{array}$ \\
\hline $\begin{array}{l}\text { Ebid } \\
\text { et al. }{ }^{19)}\end{array}$ & $\begin{array}{l}\text { Chronic } \\
\text { diabetic foot } \\
\text { ulcer }(n=40) \\
\text { Age } \\
(\text { mean } \pm \text { SD): } \\
58.17 \pm 9.83\end{array}$ & WSA & $\begin{array}{l}\text { Group } 1(\mathrm{n}=20) \text { : HILT (Nd-YAG), } 5 \mathrm{~mm} \text { probe and energy density of } \\
4 \mathrm{~J} / \mathrm{cm}^{2} \text { at a } 1 \mathrm{~cm} \text { distance from ulcer surface. P1: fast MS; P2: fixed } \\
\text { points; P3: slow MS. } 24 \text { sessions ( } 8 \text { weeks), } 3 \text { days per week } \\
\text { Group } 2 \text { ( } \mathrm{n}=20) \text { : Standard medical therapy including hypoglycaemic } \\
\text { medications such as insulin injections, systemic antibiotics, debride- } \\
\text { ment, irrigation of the wound by normal saline solution, dressing, } \\
\text { sterile gauze }\end{array}$ & $\begin{array}{l}\text { HILT was more ef- } \\
\text { fective }(\mathrm{p}<0.05) \text { than } \\
\text { standard medical } \\
\text { therapy in patients with } \\
\text { chronic diabetic foot } \\
\text { ulcers (WSA was } 0.65 \pm \\
0.58 \text { for group } 1 \text { and } 6.4 \\
\pm 2.22 \text { for group } 2 \text { ) }\end{array}$ \\
\hline
\end{tabular}

Group 1 ( $\mathrm{n}=22)$ : HILT (Nd-YAG), $3 \mathrm{KW}$ with an energy density of $510 \mathrm{~mJ} / \mathrm{cm}^{2}$, a wavelength of $1064 \mathrm{~nm}$, probe was kept perpendicular at a $1 \mathrm{~cm}$ distance from the wound surface. P1: fast MS $\left(510 \mathrm{~mJ} / \mathrm{cm}^{2}\right.$, energy of $10 \mathrm{~J} / \mathrm{cm}^{2}$, and a total energy of 70-80 J); P2: 10 fixed points

Chronic

Basala- diabetic foot

mah ulcer $(n=43)$

et al. ${ }^{20)} \quad$ Age

$($ mean $\pm \mathrm{SD})$ :

$55.14 \pm 6.52$

Neuropathic foot ulcers in children with Ebid spina bifida et $^{2}{ }^{21)} \quad(n=39)$

Age

(mean $\pm \mathrm{SD})$ :

$10.99 \pm 2.52$
WSA treatment session (10 J/point); P3: slow MS $\left(510 \mathrm{~mJ} / \mathrm{cm}^{2}\right.$, energy of $10 \mathrm{~J} / \mathrm{cm}^{2}$, and a total energy of 70-80 J), 3 sessions per week for 8 weeks, 8 mins at each

Group 2 ( $\mathrm{n}=21$ ): Sham laser

Both groups received standard medical treatment including good glycaemic control, adequate nutrition, off-loading (via bed rest or casts), local care (moist dressings and topical management), lessening of oedema, surgical debridement of devitalised wound tissue and antibiotic therapy

Group 1 ( $\mathrm{n}=19$ ): HILT (Nd-YAG), $3 \mathrm{~kW}$ with an energy density of $510 \mathrm{~mJ} / \mathrm{cm}^{2}$, a wavelength of $1064 \mathrm{~nm}$, probe was kept perpendicular at a $1 \mathrm{~cm}$ distance from the wound surface. P1: fast MS $\left(510 \mathrm{~mJ} / \mathrm{cm}^{2}\right.$, energy of $25 \mathrm{~J} / \mathrm{cm}^{2}$, and a total energy of 100-125 J); P2: 10 fixed point $(10 \mathrm{~J} /$ point $) ;$ P3: slow MS $\left(510 \mathrm{~mJ} / \mathrm{cm}^{2}\right.$, energy of $10 \mathrm{~J} / \mathrm{cm}^{2}$, and a total energy of 70-80 J), 3 sessions per week for 10 weeks, 10 mins at each

WA treatment session

Group 2 ( $\mathrm{n}=20)$ : Sham laser

Both groups received pressure relief and protection for individuals with sensory impairment and compression therapy for persistent leg oedema, wound dressings (nonadherent gauze pads, hydrogels, hydrocolloids, and absorbent foam dressings), sharp debridement procedures (when needed), oral antibiotic therapy (when required)
Summary of results

HILT was more ef-

fective $(\mathrm{p}<0.05)$ than

standard medical

therapy in patients with

chronic diabetic foot

0.58 for group 1 and 6.4

\pm 2.22 for group 2)

HILT group significantly $(\mathrm{p}<0.0001)$ improved WSA $\left(0.89 \pm 0.58 \mathrm{~cm}^{2}\right)$ more than placebo laser group $\left(4.21 \pm 0.46 \mathrm{~cm}^{2}\right)$ after 8 -weeks

The combination of HILT and standard wound care had significantly better outcomes in terms of WSA $(0.29$ $\left.\pm 0.25 \mathrm{~cm}^{2}\right)$ and WA $(17.52 \pm 1.66)$ than the placebo group $(3.24 \pm$ $0.44 \mathrm{~cm}^{2}$ and $38.11 \pm$ 3.17 , respectively) scanning. 
Table 3. Risk of bias assessment of included studies

\begin{tabular}{lccc}
\hline \multirow{2}{*}{ Items } & \multicolumn{3}{c}{ Study } \\
\cline { 2 - 4 } & Ebid et al. ${ }^{19)}$ & ${\text { Basalamah et al. }{ }^{20)}}^{\left.\text {Ebid et al. }^{21}\right)}$ \\
\hline Eligibility criteria & Yes & Yes & Yes \\
Random allocation & Yes & Yes & Yes \\
Concealed allocation & No & No & No \\
Baseline comparability & Yes & Yes & Yes \\
Blind participants & No & No & No \\
Blind therapists & No & No & No \\
Blind assessors & No & No & No \\
Adequate follow-up & No & Yes & Yes \\
Intention to treat analysis & No & No & No \\
Between-group comparisons & Yes & Yes & Yes \\
Point estimates and variability & Yes & Yes & 5 \\
Total score for each study & 4 & 5 & \\
\hline
\end{tabular}

\section{DISCUSSION}

This review found that HILT can be considered as a safe treatment option for patients with foot ulcers. The combination of HILT and standard medical therapy significantly improved outcomes more than using sham laser with standard medical therapy in terms of WSA and WA. The risk of bias assessment indicated that all studies were rated as fair quality.

HILT is a class IV laser which has been reported to have anti-inflammatory, analgesic and wound healing effects that can assist in the management of patients with musculoskeletal disorders ${ }^{9-12,14,19-21)}$. Furthermore, laser therapy also has the ability to improve the local blood circulation, blood vessel permeability and cell metabolism ${ }^{22}$. The results of this study are in consistent with a recent study conducted by Mahran et al. ${ }^{23)}$, who found that HILT had facilitating effects in reducing WSA in diabetic rats. According to a meta-analysis ${ }^{24)}$, laser therapy has beneficial healing effects such as accelerating inflammation, increasing collagen synthesis and tensile strength, reduction in healing time and decreasing wound size. Although this meta-analysis included 24 studies, they only investigated the efficacy of LLLT on wound healing.

HILT has been shown to be effective in treating patients with foot ulcers, however, there were some differences in HILT protocol (including parameters) and control treatments in the included studies, which may influence the quality of these studies. Only two ${ }^{20,21)}$ out of three studies reported HILT parameters such as fluency $\left(\mathrm{mJ} / \mathrm{cm}^{2}\right)$, radiant exposure $\left(\mathrm{mJ} / \mathrm{cm}^{2}\right)$ and the total energy (J) used. In addition, these parameters were not similar between both studies (Table 2). This study has some limitations that may limit the generalisability of the results, only three available studies (with small sample size) were included and there were methodological issues (improper reporting of allocation concealment, lack of blinding of participants, therapists and assessors). This review did not include non-English language studies. In addition, heterogeneity was high, so meta-analysis was not conducted. In summary, HILT is considered as an effective modality for wound healing in patients with foot ulcers, however further high-quality studies with large sample sizes are required to confirm its efficacy.

\section{Conflict of interest}

The author declares that he has no competing interests.

\section{REFERENCES}

1) Mayfield JA, Reiber GE, Sanders LJ, et al.: Preventive foot care in people with diabetes. Diabetes Care, 1998, 21: 2161-2177. [Medline] [CrossRef]

2) Palumbo PJ, Melton LJ: Peripheral vascular disease and diabetes. Diabetes Am, 1995, 2: 401-408.

3) Abbott CA, Carrington AL, Ashe H, et al. North-West Diabetes Foot Care Study: The North-West Diabetes Foot Care Study: incidence of, and risk factors for, new diabetic foot ulceration in a community-based patient cohort. Diabet Med, 2002, 19: 377-384. [Medline] [CrossRef]

4) Ramsey SD, Newton K, Blough D, et al.: Incidence, outcomes, and cost of foot ulcers in patients with diabetes. Diabetes Care, 1999, 22: 382-387. [Medline] [CrossRef]

5) Schaper NC, Van Netten JJ, Apelqvist J, et al. International Working Group on the Diabetic Foot: Prevention and management of foot problems in diabetes: a Summary Guidance for Daily Practice 2015, based on the IWGDF Guidance Documents. Diabetes Metab Res Rev, 2016, 32: 7-15. [Medline] [CrossRef]

6) Pound N, Chipchase S, Treece K, et al.: Ulcer-free survival following management of foot ulcers in diabetes. Diabet Med, 2005, 22: 1306-1309. [Medline] [CrossRef]

7) Reiber GE, Vileikyte L, Boyko EJ, et al.: Causal pathways for incident lower-extremity ulcers in patients with diabetes from two settings. Diabetes Care, 1999, 
22: 157-162. [Medline] [CrossRef]

8) Cammarata F, Wautelet M: Medical lasers and laser-tissue interactions. Phys Educ, 1999, 34: 156. [CrossRef]

9) Santamato A, Solfrizzi V, Panza F, et al.: Short-term effects of high-intensity laser therapy versus ultrasound therapy in the treatment of people with subacromial impingement syndrome: a randomized clinical trial. Phys Ther, 2009, 89: 643-652. [Medline] [CrossRef]

10) Alayat MS, Elsoudany AM, Ali ME: Efficacy of multiwave locked system laser on pain and function in patients with chronic neck pain: a randomized placebocontrolled trial. Photomed Laser Surg, 2017, 35: 450-455. [Medline] [CrossRef]

11) Alayat MS, Atya AM, Ali MM, et al.: Long-term effect of high-intensity laser therapy in the treatment of patients with chronic low back pain: a randomized blinded placebo-controlled trial. Lasers Med Sci, 2014, 29: 1065-1073. [Medline] [CrossRef]

12) Alayat MS, Aly TH, Elsayed AE, et al.: Efficacy of pulsed Nd:YAG laser in the treatment of patients with knee osteoarthritis: a randomized controlled trial. Lasers Med Sci, 2017, 32: 503-511. [Medline] [CrossRef]

13) Alayat MS, Elsodany AM, El Fiky AA: Efficacy of high and low level laser therapy in the treatment of Bell's palsy: a randomized double blind placebocontrolled trial. Lasers Med Sci, 2014, 29: 335-342. [Medline] [CrossRef]

14) Thabet AA, Mahran HG, Ebid AA, et al.: Effect of pulsed high intensity laser therapy on delayed caesarean section healing in diabetic women. J Phys Ther Sci, 2018, 30: 570-575. [Medline] [CrossRef]

15) Thabet AA, Elsodany AM, Battecha KH, et al.: High-intensity laser therapy versus pulsed electromagnetic field in the treatment of primary dysmenorrhea. J Phys Ther Sci, 2017, 29: 1742-1748. [Medline] [CrossRef]

16) Alayat MS, Abdel-Kafy EM, Elsoudany AM, et al.: Efficacy of high intensity laser therapy in the treatment of male with osteopenia or osteoporosis: a randomized placebo-controlled trial. J Phys Ther Sci, 2017, 29: 1675-1679. [Medline] [CrossRef]

17) Thabet AA, Alshehri MA: Effect of pulsed high-intensity laser therapy on pain, adhesions, and quality of life in women having endometriosis: a randomized controlled trial. Photomed Laser Surg, 2018, 36: 363-369. [Medline] [CrossRef]

18) Maher CG, Sherrington C, Herbert RD, et al.: Reliability of the PEDro scale for rating quality of randomized controlled trials. Phys Ther, 2003 , 83: 713-721. [Medline]

19) Ebid AA, Thabet AA, Helal OF: Effect of pulsed high intensity Nd: YAG laser in treatment of chronic diabetic foot ulcer. Int J Inf Sci Cult, 2011, 7: 25-30.

20) Basalamah MA, Ebid AA, Thabet AA, et al.: Effect of pulsed high intensity laser in treatment of diabetic foot ulcer: a randomized controlled study. Jokull, 2013, 63: 171-179.

21) Ebid AA, El-Kafy EM, Alayat MS: Effect of pulsed Nd:YAG laser in the treatment of neuropathic foot ulcers in children with spina bifida: a randomized controlled study. Photomed Laser Surg, 2013, 31: 565-570. [Medline] [CrossRef]

22) Kujawa J, Zavodnik L, Zavodnik I, et al.: Effect of low-intensity (3.75-25 J/cm2) near-infrared ( $810 \mathrm{~nm})$ laser radiation on red blood cell ATPase activities and membrane structure. J Clin Laser Med Surg, 2004, 22: 111-117. [Medline] [CrossRef]

23) Mahran HG, Faruk EM, ElSawy NA, et al.: Pulsed high intensity laser versus low intensity laser on healing of full thickness wound in diabetic rats. Int J Pharma Bio Sci, 2017, 8: 874-888. [CrossRef]

24) Woodruff LD, Bounkeo JM, Brannon WM, et al.: The efficacy of laser therapy in wound repair: a meta-analysis of the literature. Photomed Laser Surg, 2004, 22: 241-247. [Medline] [CrossRef] 